\title{
The Peterborough Schools Nutrition Project: a multiple intervention programme to improve school-based eating in secondary schools
}

\author{
Linda Parker* and Ann Fox \\ Community Nutrition and Dietetic Department, The City Health Clinic, North Peterborough Primary Care Trust, \\ Wellington Street, Peterborough PE1 5DU, UK
}

Submitted 6 December 2000: Accepted 18 May 2001

\begin{abstract}
Objective: To evaluate over two years the effectiveness of multiple interventions targeted at lunches in secondary schools with the aim of increasing the consumption of healthier foods by children during the school day.

Design: Controlled comparison study of two intervention schools targeted with multiple interventions to increase both the availability and the number of pupils consuming healthier foods, and one control school with no interventions but with the same observations over a two-year period.

Setting: Three secondary schools in Peterborough, England.

Subjects: Secondary school children in the three schools taking school lunches between 1996 and 1998.

Results: School Food Groups (SFGs) were set up in both intervention schools. All catering interventions were actioned via the SFGs. Of the food availability targets, only the target to increase the availability of high-fibre bread in both intervention schools was met. The availability of food items at the control school remained stable. The proportion of pupils consuming fruit and vegetables/salad was very low in all schools at baseline. There were positive changes for consumption of fruit and nonfried potato in one intervention school, and for high-fibre bread and non-cream cakes at the other in the short term, but only that for high-fibre bread was close to being sustained at the end of the two years. The dietary consumption target for vegetables/salad was achieved by the final monitoring period in one school.

Conclusion: Overall there were no significant changes in school-based eating at the end of the study. Some positive changes were made, with some of the dietary targets being achieved at an early stage but not sustained. Ultimately this study has shown how difficult it is to achieve sustained dietary changes in the eating habits of secondary school children, even with considerable input.
\end{abstract}

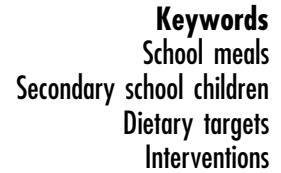

Keywords Interventions
Evidence from studies of young peoples' eating habits, both at the time of this project and since, raises growing concern about their dietary intakes and the implications for their future health ${ }^{1,2}$. An earlier project to look at food availability within the school community, and the knowledge, attitude and behaviour of school children towards healthy eating, was carried out in three co-educational secondary schools in Peterborough during the 1994-95 academic year. This project found that knowledge and attitude towards healthy eating were not reflected in the food choices made at school meals. Three other UK studies looked at knowledge, attitude and behaviour of secondary school pupils. Their findings strongly mirrored those of the earlier Peterborough project and gave support to the belief that the problems and issues raised are consistent throughout the $\mathrm{UK}^{3-5}$. This formed the starting point for the Peterborough Schools Nutrition Project (PSNP).

The Health Education Authority (HEA) later published a review of health promotion interventions to promote healthy eating in the general population, which included interventions in schools and university settings ${ }^{6}$. Only one-third of the 21 interventions in schools and universities identified in this review was judged to be of good quality and none of them was conducted in the UK. A range of different interventions was used in the studies, some in isolation but usually combined with others. Modification of school meals was rarely addressed. 
Table 1 Schools' pupil and socio-economic profiles (based on free school meal entitlement (FSME))

\begin{tabular}{lccc}
\hline & $\begin{array}{c}\text { Total number of pupils } \\
\text { at January 1996 }\end{array}$ & $\begin{array}{c}\text { Pupils with } \\
\text { FSME }\end{array}$ & $\begin{array}{c}\text { \% of pupils } \\
\text { with FSME }\end{array}$ \\
\hline School 1 & 680 & 259 & 38 \\
School 2 & 697 & 157 & 23 \\
School 3 & 1292 & 248 & 19 \\
\hline
\end{tabular}

The PSNP moves away from the concept of improved knowledge leading to improved behaviour. It was designed to evaluate over time the effectiveness of multiple interventions targeted at school meals in secondary schools, and it sought to answer whether such interventions would bring about changes in the consumption of healthier foods by secondary school children during the school day.

\section{Methods}

\section{Schools}

The study was carried out between 1996 and 1998 in three secondary schools within Peterborough already recruited in the earlier Peterborough project. These were chosen to reflect the socio-economic and ethnic profile of Peterborough's urban area. Free school meal entitlement (FSME) was used as a measure of socio-economic status of the surrounding area (see Table 1).

Schools 1 and 3 were selected as the intervention schools, having the highest and lowest proportion of pupils with FSME, and School 2 was selected as the control school, having a proportion of pupils with FSME midway between the range set by Schools 1 and 3 .

\section{Dietary targets}

Dietary targets were set as outcome measures with the aim of moving pupils' eating habits towards those recommended in The Health of the Nation ${ }^{7}$ and the Caroline Walker Trust's Nutritional Guidelines for School Meals ${ }^{8}$.

Targets were set for:

- increases in the number of pupils consuming the foods from the school dining hall; and

- increases in the availability of certain foods provided by the school caterers.

The targets (see Table 2) were set to address intakes of sugar, fat and fibre in the diet in recognition of their role in the aetiology of dental caries, obesity, coronary heart disease, stroke and some cancers. Using data from the earlier Peterborough project and in consultation with the school caterers, the targets were set as positive goals. Prohibitive targets to reduce the consumption of foods from the crisps and confectionery food groups were avoided in order to maintain consistent, positive dietary targets.

The school caterers identified what they felt to be realistic increases for the availability of the foods they provided. Consumption targets were in keeping with these increases, in recognition of the aim of minimum wastage.

\section{Interventions}

The interventions used were as follows.

School Food Groups (SFGs)

A school-based group consisting of staff, caterers and health professionals, providing a forum for initiating positive changes in the food provision and eating environment within the school, and also to facilitate better links between nutrition education and food provision. The areas targeted were the establishment of communication networks, pupil involvement, food availability and eating environment.

\section{Catering - food availability}

Strategies to increase the availability and uptake of healthier food choices using discreet techniques to promote these choices. The areas targeted were proportion and positioning of healthier options.

\section{Catering - eating environment}

Positive changes to make the eating environment more consumer-friendly and attractive in order to encourage the pupils to eat in school. The areas targeted were provision of fast food areas for healthier options, provision of crockery, shorter queues and entertainment.

\section{Peer-related and curriculum activities}

Working with teachers and pupils in novel ways. Areas targeted were use of drama in workshops and/or as a production and input to planned Personal \& Social Education (PSE) lessons on food and health.

Table 2 Dietary targets

\begin{tabular}{|c|c|c|}
\hline Food group & School meals catering availability (foods provided) & Proportion of pupils consuming \\
\hline $\begin{array}{l}\text { Fresh fruit } \\
\text { Vegetables and salad } \\
\text { High-fibre bread }\end{array}$ & $\begin{array}{l}\text { Increase by a minimum of } 50 \% \\
\text { Increase by a minimum of } 50 \% \\
\text { Increase by } 100 \%\end{array}$ & $\begin{array}{l}\text { From } 19 \% \text { to } 28 \% \\
\text { From } 18 \% \text { to } 27 \% \\
\text { (School } 1 \text { ) from } 18 \% \text { to } 36 \% \\
\text { (School } 3 \text { ) from } 10 \% \text { to } 20 \%\end{array}$ \\
\hline Non-fried potato & Increase by a minimum of $66 \%$ & From $6 \%$ to $10 \%$ \\
\hline Non-cream cakes & Increase by a minimum of $50 \%$ & From $26 \%$ to $39 \%$ \\
\hline
\end{tabular}


Table 3 Interventions carried out in School 1

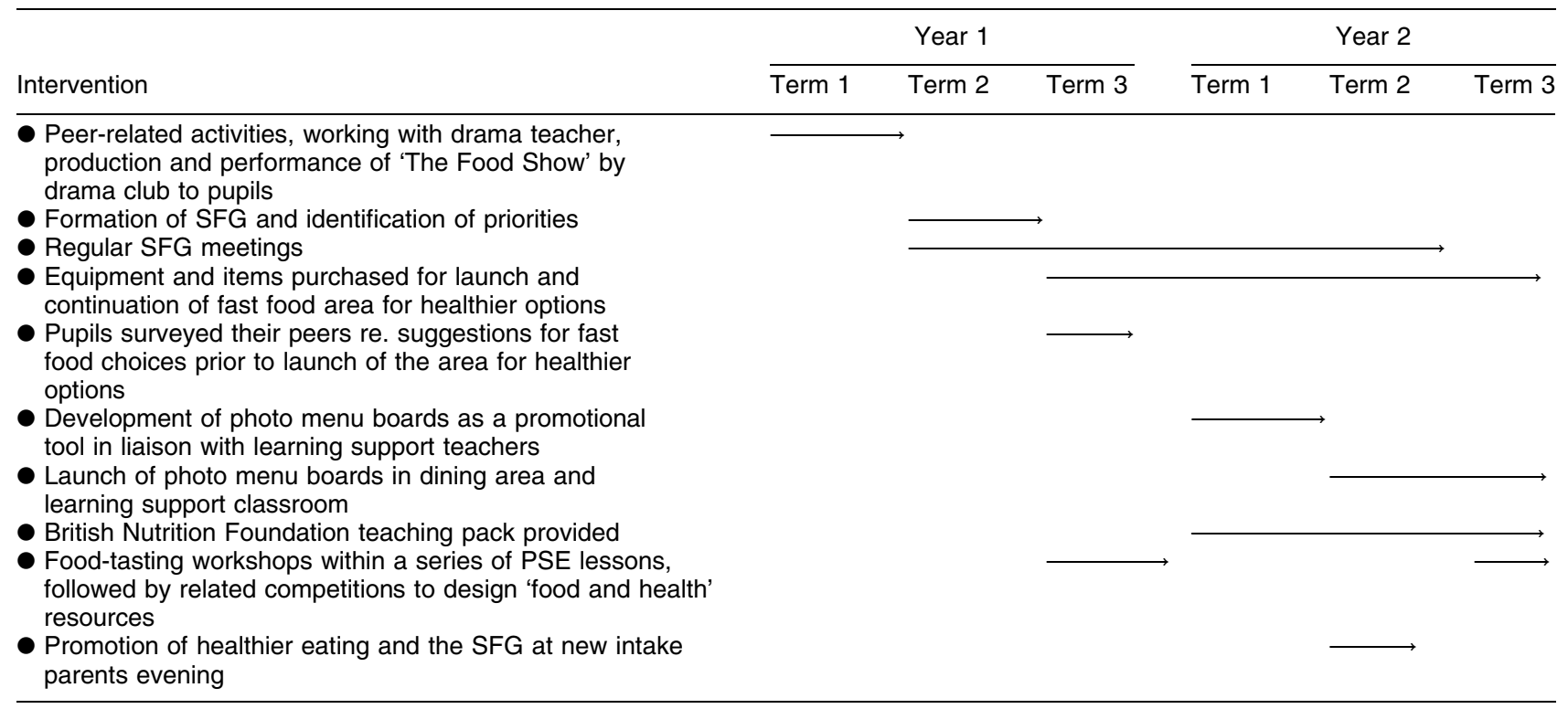

At initial meetings with the liaison teacher at each school, a clear priority order for implementing the interventions was identified according to the individual schools' needs (see Tables 3 and 4).

\section{Monitoring}

Data were collected through a programme of monitoring as summarised in Table 5. Monitoring took part over the entire two years (six terms) of the study.

The methods used for both the interventions and monitoring were not validated.

\section{Sample size and statistics for observational data}

Based upon uptake of school food (Cambridgeshire County Council School Census - January 1995), and with four meal break observations being made per school per term, data for school food would be collected on a minimum of 1012 pupils (per study school) and 772 pupils (control school) per term.

Power calculations were made to detect a shift in trends across the whole school towards the dietary targets with $5 \%$ significance and $80 \%$ power. A minimum of 765 observations per school per monitoring period was required in order to detect statistically significant changes. It was assumed that if the targets for increased consumption were met then food availability targets must also have been achieved.

\section{Data analyses}

Data from the weekly School Meals Catering food production sheets were collated per school for each

Table 4 Interventions carried out in School 3

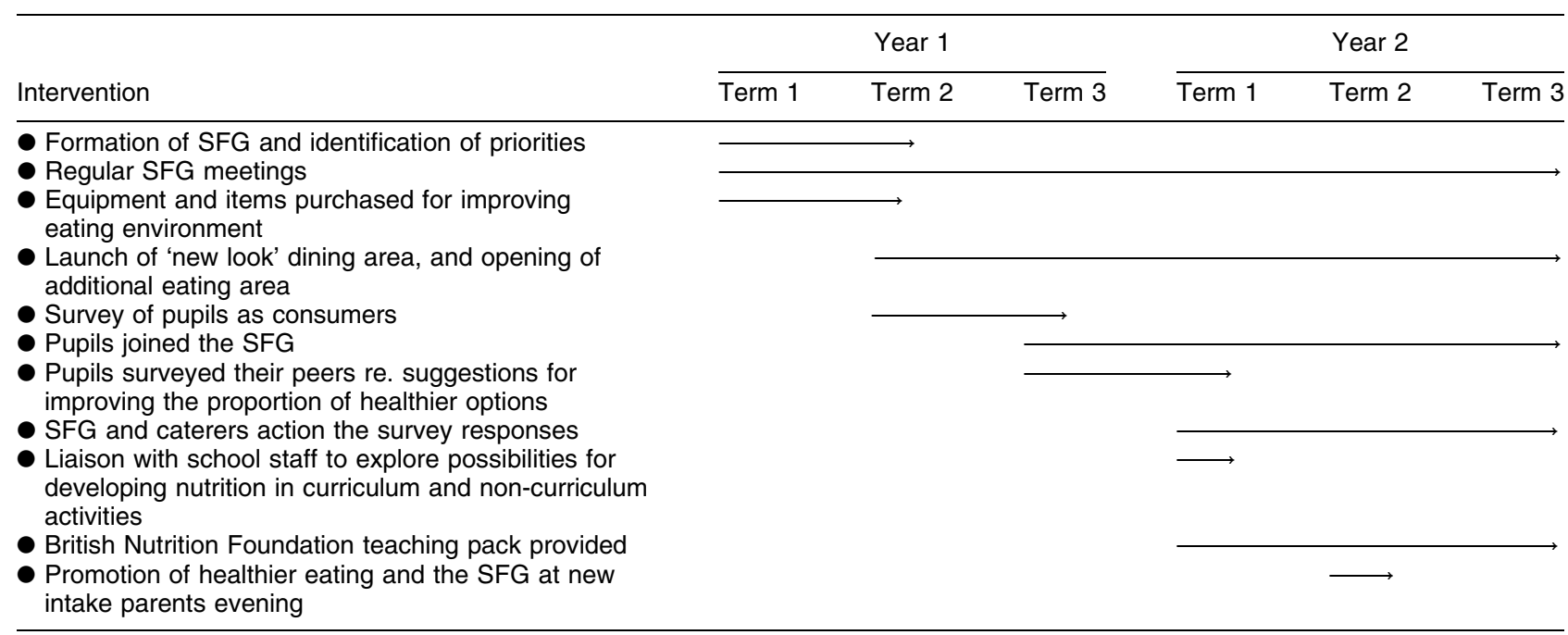


Table 5 Monitoring methods and frequency over the two years (six terms)

\begin{tabular}{lll}
\hline & \multicolumn{1}{c}{ Method } & \multicolumn{1}{c}{ Frequency } \\
\hline $\begin{array}{l}\text { School meals catering } \\
\text { Foods produced }\end{array}$ & $\begin{array}{l}\text { Collection of food production sheets with numbers } \\
\text { of portions of foods produced from each head cook } \\
\text { Observation of frequency of food categories consumed } \\
\text { by individual pupils over lunch-times } \\
\text { Mean number of pupils observed over lunch-times }\end{array}$ & $\begin{array}{l}\text { One 8-week monitoring period per term per school } \\
\text { within each 8-week monitoring period } \\
\text { Once at end of each 8-week monitoring period }\end{array}$ \\
\hline
\end{tabular}

dietary target to provide a mean weekly figure over each 8-week monitoring period.

The observational data collected with respect to foods consumed in each school were entered into SPSS for Windows files. Data were analysed using SPSS. The frequencies of consumption for each of the foods being monitored over each observation period were calculated. From these, mean and standard error were calculated for each monitoring period and plotted over time. Pooled $t$ tests were used to compare the results from each observation period with baseline, i.e. change relative to baseline consumption, to identify which of the dietary targets had been achieved within the study and control schools.

\section{Results}

\section{Interventions}

\section{School Food Groups (SFGs)}

Membership of the groups differed as shown below:

- School 1 - two teaching staff, school nurse, school cook, catering manager, two project workers (including community dietitian);

- School 3 - two teaching staff (reduced to one after end of Year 1), school nurse (first two terms only), school cook, catering manager, parent/governor, two pupils (from Term 3, Year 1), two project workers (including community dietitian).

SFGs met approximately once each half term. At School 1 commitment to the group by teaching staff lapsed during Term 2 of Year 2 and meetings ceased by Term 3.

\section{Catering - food availability}

Adjustments to the proportion and positioning of healthier food options were made by the caterers in both of the intervention schools as a result of feedback from project workers and from results of pupils' surveys.

The proportion of high-fibre bread was increased in two stages. Firstly, more sandwiches and rolls were produced while higher-fat options, e.g. sausage rolls, were reduced. Secondly, more of these sandwiches and rolls were made from high-fibre bread using the more popular fillings.

The proportion of non-fried potato was increased at
School 1 by introducing a jacket potato bar as a fast food area for healthier options. This followed pupils' responses to a questionnaire, designed and carried out by GNVQ pupils, on preferred prices and fillings.

Adjustments were made to the position and display of healthier options. This included the jacket potato bar as an extra service point at School 1 and a salad 'cart' at School 3. Attempts were made to position items such as fruit near to the tills but this was not always achieved on a daily basis.

\section{Catering - eating environment}

Changes to the eating environment were achieved in both intervention schools. In School 1 the dining area was set up daily within the school hall and therefore the scope for interventions was restricted. The project funded the purchase of equipment for establishing a fast food area for healthier options, including a jacket potato oven for filled jacket potatoes and a salad bar area. Caterers provided an additional till for this area, facilitating speed of service and shorter queues. A photo menu board to promote healthier combinations of foods was produced in conjunction with the learning support staff.

In School 3 the pupils from the SFG designed and carried out user satisfaction surveys which identified areas for improvement. As a result new tables and chairs for the existing purpose-built dining area were provided, enabling the old furniture to be used in a newly created eating area within another part of the school. This area provided an additional school meals' service point, thus reducing queues. The PSNP funded the purchase of new crockery and trays, a soup kettle, a hot drinks machine, serving dishes and music systems for each eating area. The caterers provided a heated gantry for hot food and made improvements to the decor.

\section{Peer-related and curriculum activities}

The interventions using peer-related activities were only supported by study School 1. These included the production of 'The Food Show' by the after-school drama club, food-tasting workshops within PSE lessons and pupil competitions to produce promotional resources for healthier choices to be displayed in school.

\section{Monitoring}

Table 6 shows the numbers of pupils observed having a 
Table 6 Number $(n)$ and percentage of pupils observed consuming school meals within all three schools

\begin{tabular}{|c|c|c|c|c|c|c|c|c|c|c|c|c|}
\hline & \multicolumn{12}{|c|}{ Monitoring period } \\
\hline & \multicolumn{2}{|c|}{0 (Baseline) } & \multicolumn{2}{|c|}{1} & \multicolumn{2}{|c|}{2} & \multicolumn{2}{|c|}{3} & \multicolumn{2}{|c|}{4} & \multicolumn{2}{|c|}{5} \\
\hline & $n$ & $\%$ & $n$ & $\%$ & $n$ & $\%$ & $n$ & $\%$ & $n$ & $\%$ & $n$ & $\%$ \\
\hline School 1 & 1029 & 28 & 979 & 27 & 1199 & 31 & 1122 & 30 & 921 & 25 & 1255 & 34 \\
\hline School 3 & 1077 & 12 & 1152 & 14 & 1499 & 17 & 1356 & 15 & 1188 & 13 & 1364 & 14 \\
\hline School 2 & 1091 & 26 & 1033 & 25 & 1291 & 29 & 1230 & 26 & 1118 & 24 & 1401 & 31 \\
\hline
\end{tabular}

school meal (and expressed as a percentage of total pupils) in both intervention schools (Schools 1 and 3) and in the control school (School 2). 'Monitoring period 0' relates to the first 8 -week monitoring period and provides the baseline for the further observations of this two-year study.

\section{Dietary targets}

Foods consumed by pupils

Fruit consumption. The mean numbers of pupils choosing fruit at baseline were very low, less than 10 in Schools 1 and 3 and less than five in School 2. The dietary target for fruit (50\% increase) was achieved in School 1 during monitoring periods 2 and 3, with 12.5 and 13.8 pupils respectively, but was not sustained to the end of the study. The target was not attained at any point at School 3, with a statistically significant change in the wrong direction at period $5(P<0.01)$. There was very little change in fruit consumption at the control school.

Vegetable and salad consumption. The mean numbers of pupils consuming vegetables and salads were again very low at baseline in all three schools, with less than 10 in Schools 1 and 3 and less than four in the control school. School 1 did achieve the dietary target (50\% increase) during the final monitoring period, with 15.3 pupils $(P<$ $0.01)$. This was largely due to the increased uptake of preordered plated salads. Further observations are necessary to verify that this increase can be maintained and does not reflect a 'novelty' effect. School 2 had an unexpectedly significant increase at period 2 with 10 pupils $(P<0.001)$ but showed a decline thereafter, although it was still significantly higher $(P<0.01)$ at the end of the study.

High-fibre bread consumption. The amount of highfibre bread consumed as a percentage of all bread chosen was very different in all three schools. At baseline, study Schools 1 and 3 had 25.4\% and 9.3\% respectively, whilst School 2 did not provide high-fibre bread. In School 3 the target (100\% increase) was achieved in period 1, with $26.3 \%$ of pupils, which was largely sustained for the duration of the study at the $P<0.05$ level. The proportion of high-fibre bread consumed in School 1 was variable, with a fall from $39.8 \%$ to $12.6 \%$ between monitoring periods 2 and 4, rising again to $37.6 \%$ at the end of the study. The exact cause of these fluctuations was unclear. The control school showed no change in the type of bread consumed since it continued to offer only white bread.

Non-fried potato consumption. The amount of nonfried potato consumed as a percentage of all potato chosen was less than $10 \%$ at baseline in all three schools. In School 1, a significant negative change occurred at period 1 with a fall to $2 \%(P<0.01)$, but the target of a $66 \%$ increase was exceeded during period 3 with the proportion rising to $14.2 \%$. This coincided with the launch of the fast food area for filled jacket potatoes. Although this level of consumption was not sustained, it remained higher than at baseline for the remaining monitoring periods. School 3 showed a change in the wrong direction from period 1 onwards, the proportion of only $1.1 \%$ having become significant by period $5(P<0.001)$. A possible explanation is the opening of the newly created eating area, which offered a faster service but only chips as a potato option. There was little change in consumption trends at the control school.

Non-cream cake consumption. Non-cream cake was defined as cakes or buns neither deep-fried nor with cream added. The amount of non-cream cake consumed as a percentage of all cake/buns chosen was between $37 \%$ and $38.4 \%$ at baseline in all three schools. School 3 achieved the target (50\% increase) for the consumption of non-cream cake during periods 2 and 3 with $59.4 \%(P<$ 0.01 ) and $57.4 \%$ respectively. This was sustained until the final monitoring period when consumption decreased again to $42 \%$.

School 1 showed a negative change up to period 3 with the proportion falling to $28 \%$, and thereafter a marked rise to $45.3 \%$ by period 5 although this was not significant. The control school showed little change for most of the study but a statistically significant drop to $13.2 \%$ was seen at the final monitoring period $(P<0.01)$.

\section{Foods produced by school catering service}

Those food groups targeted were recorded as portions per week (fresh fruit and vegetables and/or salad) or as a percentage of the food group (high-fibre bread, non-fried potatoes and non-cream cake), and are shown in Table 7 together with 95\% confidence intervals (CIs). The mean production figure for each food group in each observation period was used to calculate the $95 \%$ CI. Only one of the food production targets was achieved and sustained 
Table 7 Number of portions per week or proportions of food groups produced by school caterers and the $95 \% \mathrm{Cls}$

\begin{tabular}{|c|c|c|c|c|c|c|c|c|c|}
\hline \multirow[b]{3}{*}{ Food group } & \multicolumn{6}{|c|}{ Study schools } & \multirow{2}{*}{\multicolumn{3}{|c|}{$\frac{\text { Control school }}{\text { School } 2}$}} \\
\hline & \multicolumn{3}{|c|}{ School 1} & \multicolumn{3}{|c|}{ School 3} & & & \\
\hline & $\begin{array}{l}\text { Start } \\
\text { point }\end{array}$ & $\begin{array}{l}\text { End } \\
\text { point }^{*}\end{array}$ & $95 \% \mathrm{Cl}$ & $\begin{array}{l}\text { Start } \\
\text { point }\end{array}$ & $\begin{array}{l}\text { End } \\
\text { point }\end{array}$ & $95 \% \mathrm{Cl}$ & $\begin{array}{l}\text { Start } \\
\text { point }^{*}\end{array}$ & $\begin{array}{l}\text { End } \\
\text { point* }\end{array}$ & $95 \% \mathrm{Cl}$ \\
\hline Fresh fruit (portions/week) & $153+$ & 60 & 4 to 154 & $132 \dagger$ & 'Very little' & -35 to 255 & 33 & 32 & 29 to 41 \\
\hline Vegetables and salad (portions/week) & 281 & 132 & 50 to 283 & $150 \ddagger$ & $50 \ddagger$ & -9 to 239 & 120 & 230 & 83 to 247 \\
\hline High-fibre bread (\% of all bread) & 18 & 36 & 12 to 37 & 10 & 28 & 7 to 34 & 0 & 0 & \\
\hline Non-fried potato ( $\%$ of all potato) & 5 & 7 & 1 to 12 & 8 & 4 & 1 to 13 & 5 & 7 & 4 to 11 \\
\hline Non-cream cakes (\% of all cakes) & 25 & 33 & 22 to 40 & 23 & 25 & 8 to 45 & 18 & 22 & 12 to 34 \\
\hline
\end{tabular}

* The 'start point' relates to figures provided by caterers during the baseline study, i.e. before interventions took place. The 'end point' relates to the last period of monitoring, i.e. period 5.

† The start point figures for fruit were very different to the subsequent figures provided by caterers throughout the study, so that interpretation of these figures is unreliable.

¥ At School 3, figures were provided for vegetables only and do not include salad.

to the end of the study, namely high-fibre bread at both study schools.

The results are broadly consistent with the consumption trends observed by direct monitoring of pupils' selection. The availability of food items at the control school remained stable with the exception of vegetables/ salad, which increased by nearly $100 \%$ although there was no apparent reason for this. Changes to the type of bread appear to be the most successful intervention.

\section{Discussion}

The PSNP was designed to be a multiple intervention programme to improve school-based eating in secondary schools. The results show that, overall, there were no significant changes in school-based eating at the end of the study. However, there were positive changes for fruit and non-fried potato in one intervention school, and high-fibre bread and non-cream cake at the other intervention school in the early stages. Only that for high-fibre bread was close to being sustained at the end of the two years. This is consistent with other studies reviewed by the HEA, particularly those studies that actually assessed changes in dietary intakes, which found no overall effect in the long term but some effect in the short term or in population sub-groups ${ }^{6}$.

Dietary targets were established as outcome measures of effectiveness. It is recognised that a limitation of this method is that it provides no information on whether the altered food choice at one meal affects the nutritional quality of the entire diet. The targets were set at the same level for both study schools. It is now recognised that these should have been set individually, taking account of each school's starting point. In evaluating the consumption targets, the assessment of effectiveness within each school was achieved by using the data from the first monitoring period, referred to as Baseline (0).

The method of data collection for food production (hence availability) was reliant upon self-reporting by school caterers. In the absence of any computerised food production figures all data supplied in this way are open to a degree of inaccuracy. Difficulties were experienced with the regular collection of this information on some occasions, due to staffing problems within the catering departments.

Preferred interventions in the PSNP were those that did not require the children to improve their knowledge of healthy eating, since knowledge and attitude towards healthy eating had been demonstrated in the earlier study not to be reflected in the food choices made at school meals. Whittaker et al. ${ }^{9}$ evaluated an intervention after 8 months to reduce dietary fat in school lunches in the USA. The need for 'passive' interventions that allow pupils to be unaware of the changes being made to foods was highlighted. The report of the US National School Nutrition Dietary Assessment Study ${ }^{10}$ recommended that, to achieve change, the whole school organisation should be involved, intensive work with food service workers and pupils is required, and lessons should be learned from commercial fast food operators about marketing 'healthier options' to attract young people.

Joint working with the caterers was successfully established and maintained through the forum of the SFGs. The SFGs proved to be very useful for driving change according to the school's priorities, and for taking ownership of the food provision within the school. The presence and support of the Catering Manager was extremely important, particularly in maintaining positive liaison between the catering staff and other SFG members. It was the intention to use School Nutrition Action Groups, in which membership by parents and pupils is considered desirable. In practice this was found to be extremely difficult. Pupils in School 3 joined only after the formation of a School Council. At School 1, teachers were initially reluctant to involve pupils, however GNVQ students did provide some input. This study has shown that the setting up and functioning of an SFG such as this requires support by senior management and endorsement by the head teacher and governors. Similarly, the School Nutrition Action Groups Evaluation 
Report ${ }^{11}$ and evaluation in England of the development of the European Network of Health Promoting Schools Project $^{12}$ found that such support was one of the most influential factors in determining the progress of the project.

In order for such a group to remain viable it was found that a high level of commitment is required, both in interest and input (particularly of time) by its members. This was more of an issue at times of staff change and was illustrated in School 1 when the long-term sickness of a key staff member led to the collapse of the SFG by the end of year 2 of the study. Similar problems have been documented elsewhere. Peach et $a l^{13}$ evaluated the concept of school food committees as part of a national health promotion project in New Zealand which targeted school food services. Many schools experienced difficulties in setting up school food committees because forming and maintaining such a committee required input from already busy school staff. The evaluation showed the need for establishing a network of facilitators to assist schools in the formation of school food committees in order to increase effectiveness in this area of health promotion.

The design of this study did not involve evaluation of individual interventions, such as the peer-related activities. Only one of the two intervention schools participated in peer-related and curriculum activities. Further development and relevant resources not available to this project are required to evaluate such interventions.

Food consumption can be affected by external factors such as weather, school trips and religious festivals. These were considered and noted on each observation visit, but were not found to have any apparent effect on pupils' consumption.

Changes to the proportions of healthier options within school meals came to be recognised as a highly influential factor in working towards the dietary targets. In practice some of the changes were easier to address than others. Increasing the quantity of fruit, vegetables and salads consumed proved to be the most difficult target in both schools. Despite increasing the availability of these foods there was little change in the uptake. The only exception to this was seen in the final monitoring period at School 1, where the system of pre-ordered plated salads provided a faster service (minimal queuing) and was considered to be 'value for money' by the pupils who made this choice. At the end of the study the caterers were looking at alternative methods, e.g. increasing the amount of salad used in filled rolls/sandwiches, adding more vegetables to main dishes, and producing more fruit-based desserts.

Changing the proportion of high-fibre bread to white bread was easier to address even though the dietary target was not achieved. It was observed that when choice was more limited at the end of the service period, the choice of filling was more influential than the type of bread.

The achievement of the target for non-fried potatoes at
School 1 was due to the introduction of the filled jacket potato bar. It is possible that its success resulted from the decreased queuing and that this fast food area was not overtly promoted as providing 'healthy' choices.

Positive attempts to improve the positioning of healthier options were made by both schools within the limitations of the space available. Whilst carrying out the observations it was noted that items in the area next to each till had a strong influence on the final combination of foods chosen. This was particularly noticeable with those pupils with a free meal ticket who would make up their allowance with whatever was close to hand, e.g. tomato sauce sachets, biscuits or fruit. Consequently, the till operators have an important role, not only in positioning healthier options in this area, but also in guiding the pupils' choices. Where extra service points were established the display of healthier options was improved. The long-term effectiveness of this as an intervention method was greatly influenced by the fluctuating staffing levels of the caterers resulting in, at times, the withdrawal of these extra service points.

The interventions targeting the eating environment were dependent not only upon the school's priorities but also on whether the dining area was sole-use. Where changes were made, although commented upon favourably by pupils, there was no noticeable increase in the throughput of pupils.

Those interventions identified as being beneficial, for example the introduction of fast food points serving filled jacket potatoes and plated salads, require further investigation to evaluate their effectiveness. It is clear that a need exists for research into other intervention strategies, particularly targeting changes at the level of food production.

\section{Conclusions}

The results show that, overall, there were no significant changes in school-based eating at the end of the study. However, some positive changes were made with some of the dietary targets being achieved at an early stage but not sustained. Ultimately this study has shown how difficult it is to achieve sustained dietary changes in the eating habits of secondary school children, even with considerable input.

\section{Acknowledgements}

This study was supported by a grant from the Anglia and Oxford Regional Health Authority. We thank all those who took part in the study, especially the heads, teaching staff and pupils at each school, and Cambridgeshire Catering Services. We also thank the following for their support and contributions: Dr Susan Jebb, Professor Andrew Prentice and Dr Alison Black of the late MRC Dunn Nutrition Centre; statisticians Dr Paul Bellaby and 
Felix Bellaby at the School of Economic and Social Studies, University of East Anglia; Helen Brown, Lead Practitioner, Lifespan Healthcare Trust, Cambridge; and Dr Joyce Hughes for editing the paper.

\section{References}

1 Department of Health. The Diets of British Schoolchildren. Report on Health and Social Subjects No. 36. London: HMSO, 1989.

2 Gregory J, Lowe S, Bates C, Prentice A, Jackson L, Smithers $\mathrm{G}$, et al. National Diet and Nutrition Survey: Young People aged 4-18 years. Vol. 1. Report of the Diet and Nutrition Survey. London: The Stationery Office, 2000.

3 Young I. Healthy eating policies in schools: an evaluation of effects on pupil's knowledge, attitudes and behaviour. Health Educ. J. 1993; 52: 3-9.

4 Morrison M. Researching food consumers in school. Recipes for concern. Educ. Studies 1995; 21(6): 239-63.

5 Devine C, Lang T, Longfield J, Maguire O, Rayner M. An Investigation into the Nutritional Quality of School Meals in Northern Ireland. Northern Ireland: Northern Ireland Chest Heart and Stroke Association, 1995.
6 Roe L, Hunt P, Bradshaw H, Rayner M. Health Promotion Interventions to Promote Healthy Eating in the General Population: A Review. Health Promotion Effectiveness Reviews No. 6. London: Health Education Authority, 1997.

7 Department of Health. The Health of the Nation: A Strategy for Health in England. London: HMSO, 1992.

8 The Caroline Walker Trust. Nutritional Guidelines for School Meals. London: The Caroline Walker Trust, 1992.

9 Whittaker RC, Wright JA, Finch AJ, Pstay BM. An environmental intervention to reduce dietary fat in school lunches. Paediatrics 1993; 19(6): 1107-11.

10 Burghardt JA, Devaney BL, Gordon AR. The School Nutrition Dietary Assessment Study: summary and discussion. Am. J. Clin. Nutr. 1995; 61(Suppl.): 252S-57S.

11 Passmore S. School Nutrition Action Groups Evaluation Report - A Study to Examine the Impact of Establishing School Nutrition Action Groups in Secondary Schools in Birmingham. Birmingham: Birmingham LEA, 1999.

12 Hickman M, Healy C. The European Network of Health Promoting Schools: development and evaluation in England. Health Educ. J. 1996; 55: 465-70.

13 Peach R, Dehar M, Casswell S, Gourley G. Heartbeat awards in intermediate and secondary schools in New Zealand: outcomes of the first two years. Health Promotion J. Aus. 1996; 6(1): 42-50. 